\title{
Seismic Soil Structure interaction for Shear wall structures
}

\author{
Marwan Sadek ${ }^{1, *}$, Fadi Hage Chehade ${ }^{1}$, Bassem $\mathrm{Ali}^{2}$, Ahmed $\mathrm{Arab}^{3}$ \\ ${ }^{1}$ Lebanese University, Faculty of Technology, Lebanon \\ ${ }^{2}$ Arab International University, Syria \\ ${ }^{3}$ Univ. UHBC of Chlef, Algeria
}

\begin{abstract}
For soft soil subjected to earthquake loading, the soil non linearity could significantly amplify the ground motion. This paper presents a 3D numerical study on the influence of soil non linearity on the seismic soil structure interaction for shear wall structures. Numerical simulations are conducted for both elastic and elastoplastic behaviour for the soil. Real ground motions records are used in the study. The analysis is focused on the seismic induced response of the soil and the structure in terms of displacement and velocity. The results show that considering elastic model for the soil behaviour is not sufficient and could significantly affect the seismic induced response of the system.
\end{abstract}

\section{Introduction}

Comparison between the conventional code design spectra and the actual response spectra show that higher values of natural period do not necessarily contribute to a smaller response, thus; the dominant assumption about the beneficial role of SSI in the structural engineering point of view represents a rough simplification correspondingly leading to an unsafe design $[1,2]$. Several researches have been conducted in order to investigate the influence of SSI on the dynamic characteristics and seismic induced response of the structures [3, 4]. Khalil et al [5] proposed a relative rigidity $\mathrm{K}_{\mathrm{ss}}$ for $3 \mathrm{D}$ framed structures. It has been shown that low value of $\left(\mathrm{K}_{\mathrm{ss}}\right)$, neglecting the SSI can lead to an inappropriate design and improper evaluation of the fundamental frequency of structures.

Several methods have been used for the assessment of SSI problems. Halabian and El Naggar [6] developed a hybrid approach to consider soil nonlinearities that may occur in the soil adjacent to the structure. The consistent infinitesimal finite-element cell method (CIFECM) and the finite-element method (FEM) were combined in the adopted approach. More recently, with high performance computing devices, the direct method seems to be the more efficient. Gullu et al. [7] considered the case of the historical masonry stone arch bridge (Matarac1 Bridge, Trabzon). A full 3D time history analysis of SSI has been applied on this bridge using the direct approach by considering the soil and structure nonlinearities. The direct method has also been used in [8] in order to account for the nonlinear soil behavior of a nuclear power plant in Lotung. The direct approach will be adopted in the

\footnotetext{
*Corresponding author: marwansadek00@gmail.com
} 
present study. On the other hand, the behaviour of the superstructure may affect significantly the soil structure interaction phenomena. Two main behaviors could be identified for bracing systems in building structure: frames and shear walls (see Fig 1). The difference between these two systems was investigated by several researchers $[9,10]$.

This papers present a 3D numerical investigation about the influence of soil behaviour on the seismic soil structure interaction in case of shear wall structure. The survey is carried out using the FLAC3D program which has been successfully used to analyze several problems of soil dynamics in both linear and nonlinear domains $[11,12]$.

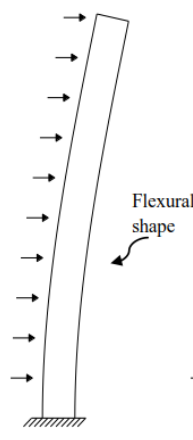

(a)

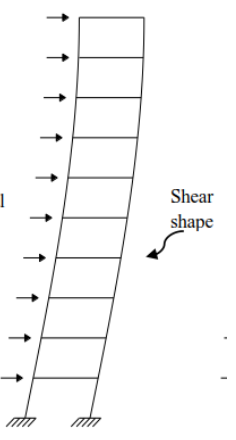

(b)

Fig. 1. Deflected Configurations of: (a) Shear Wall; (b) Rigid Frame.

\section{Numerical model - MDOF structure}

\subsection{Problem under consideration}

The studied case consists in a 3D model composed of 2 reinforced concrete shear walls connected by a reinforced concrete slab (dimensions $9 \mathrm{~m} \times 5 \mathrm{~m}$ ) with a self weight of 22.5 tons (fig. 2). The RC shear walls rest on 2 foundations of $50 \mathrm{~cm}$ depth, $4 \mathrm{~m}$ length, and $1.5 \mathrm{~m}$ width. The story height is fixed to $3 \mathrm{~m}$. The superstructure rests on a homogeneous soil layer $15 \mathrm{~m}$ thick overlying a rigid bedrock. The soil non linearity is described using Mohr Coulomb model. A cohesive soil is considered in the present study. The mechanical properties of the soil are summarized in table 1. The soil cohesion was chosen to prevent the failure under the applied load. All structural elements are made of reinforced concrete with an elastic linear behaviour (density $=2.5 \mathrm{~T} / \mathrm{m}^{3}$; Elastic modulus $\mathrm{E}=36 \mathrm{GPa}$; Poisson ratio $=0.2$ ).

The 3D finite difference mesh used in the numerical simulation is illustrated in Figure 2. It includes 17448 zones where both the soil and the structure are modelled using 8 node solid elements. A uniform mesh is taken for the whole model in order to prevent numerical problem with progressive mesh. The mesh was locally refined under the structure where the element size is $0.5 \mathrm{~m}$. The wave reflection at the boundaries is prevented using viscous absorbing boundaries. A preliminary study was carried out in order to define the position of these boundaries for the studied case. These limits depend on the characteristics of the applied seismic load and the inertial force generated by the superstructure. For the structure, local damping is considered, while for the soil, Rayleigh damping is used. 

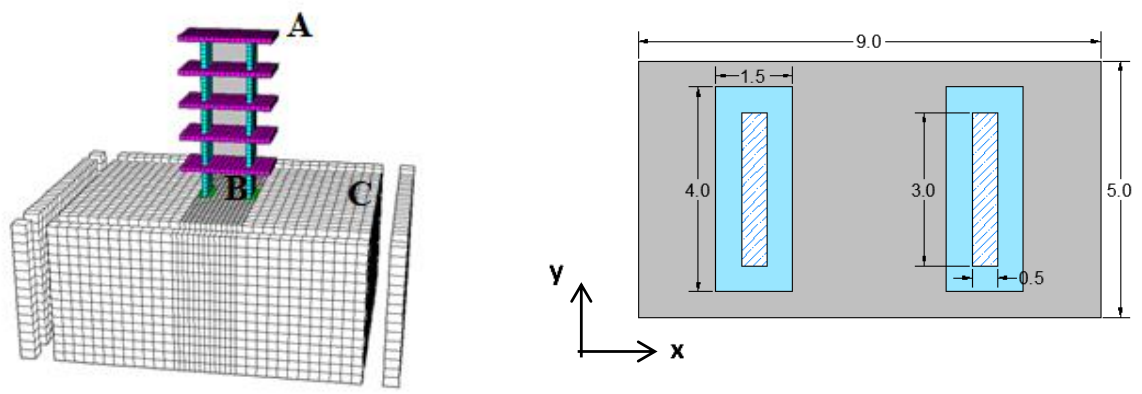

Fig. 2. Deflected Configurations of: (a) Shear Wall; (b) Rigid Frame.

Table 1. Properties of the soil.

\begin{tabular}{|c|c|c|c|c|c|c|c|c|}
\hline $\begin{array}{c}\text { Soil } \\
\text { Type }\end{array}$ & $\rho_{\mathrm{s}}(\mathbf{k g} / \mathbf{m} 3)$ & $\mathbf{E}_{\mathbf{s}}(\mathbf{M P a})$ & $\boldsymbol{v}_{\mathbf{s}}$ & $\mathbf{K}_{\mathbf{0}}$ & $\boldsymbol{\xi}_{\mathbf{s}}(\mathbf{\%})$ & $\mathbf{C}(\mathbf{k P a})$ & $\boldsymbol{\varphi}$ & $\boldsymbol{\psi}$ \\
\hline Cohesive & 1700 & 20 & 0.4 & 0.5 & 5 & 150 & 0 & 0 \\
\hline
\end{tabular}

\subsection{Dynamic characteristics}

In the analysis of a seismic problem, the first step consists in the assessment of the natural frequencies of the soil-structure system and to compare it with the frequency content of the applied load. In the studied case, the seismic motion is applied at the rigid bedrock. Figures 3 represents the velocity time history and the corresponding Fourier spectrum for Tabas earthquake that occurred on 1978 in Iran (Figure 3). The amplitude of the ground motion was scaled to fit a maximum velocity of $40 \mathrm{~cm} / \mathrm{s}$ in order to obtain an advanced plasticity in the soil. The corresponding frequency content is concentrated between 0.2 and $2 \mathrm{~Hz}$. The frequency of the multistory structure computed under the fixed base assumption, is $52 \mathrm{~Hz}$, while the flexible base natural frequency of the structure could significantly differ due to a high value of relative stiffness $\mathrm{K}_{\mathrm{ss}}$ [5]. In order to determine the natural frequencies of the system, the following procedure was adopted: The system was subjected to a forced vibration followed by a free vibration. The frequency content analysis of the free vibration part lead to the result depicted in figure 4. Two peaks appear, one at around $1.1 \mathrm{~Hz}$ which is the frequency of the soil $\left(\mathrm{f}_{\mathrm{l}}=\mathrm{V}_{\mathrm{s}} / 4 \mathrm{H}\right)$, and the other larger peak is at around $3.2 \mathrm{~Hz}$ which corresponds to the frequency of the flexible base structure. It is clear that the soil structure interaction has a great impact on the flexible base frequency of the structure.
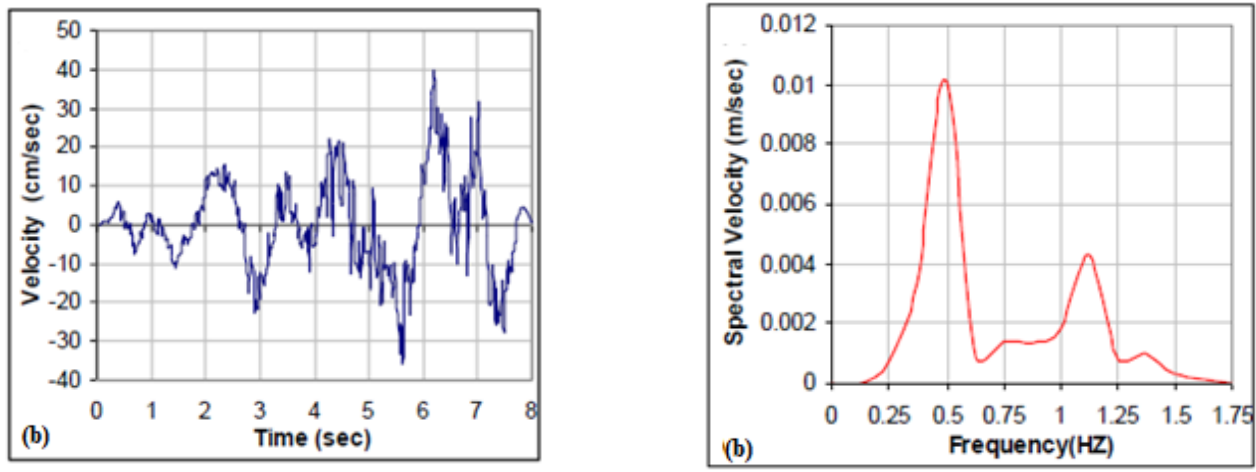

Fig. 3. Characteristics of the Ground motion - 1978 Tabas earthquake. 


\section{Fourier Spectrum}

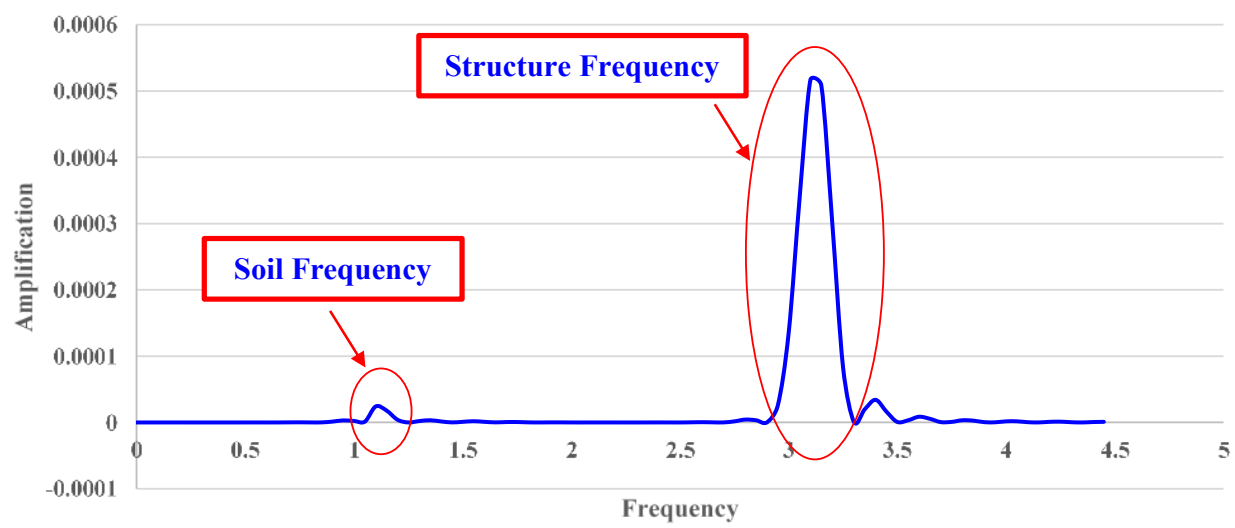

Fig. 4. Natural frequencies of the soil-structure system.

\subsection{Comparison of linear and non-linear seismic response}

In this section, the 5-story structure lying on cohesive soil is subjected to the Tabas seismic record along the y-axis. The velocity amplification for the soil located beneath the structure is depicted in Fig 5, for both elastic and elastoplastic soil behaviour. For the upper part of the soil, it can be seen a reduction of the lateral amplification when non linear behaviour is considered. The maximum amplification at the soil surface is reduced from 4.1 for elastic soil to 3.1 for elastoplastic behaviour. Table 2 compare the results obtained in terms of displacements and velocity for three different points of the system $\mathrm{A}, \mathrm{B}$, and $\mathrm{C}$ (see figure 2 ), where A is located at the top of the structure. As for the soil, the seismic induced displacement is lower in the elastoplastic model compared the elastic result. An additional damping results from the soil plasticity. The lateral displacement obtained at the top of the structure is significantly reduced to half of its value obtained for elastic behaviour. The dissipation of the energy by soil structure interaction is highly increased when non linear behaviour of the soil is considered. This effect of increased by the presence of the structure.

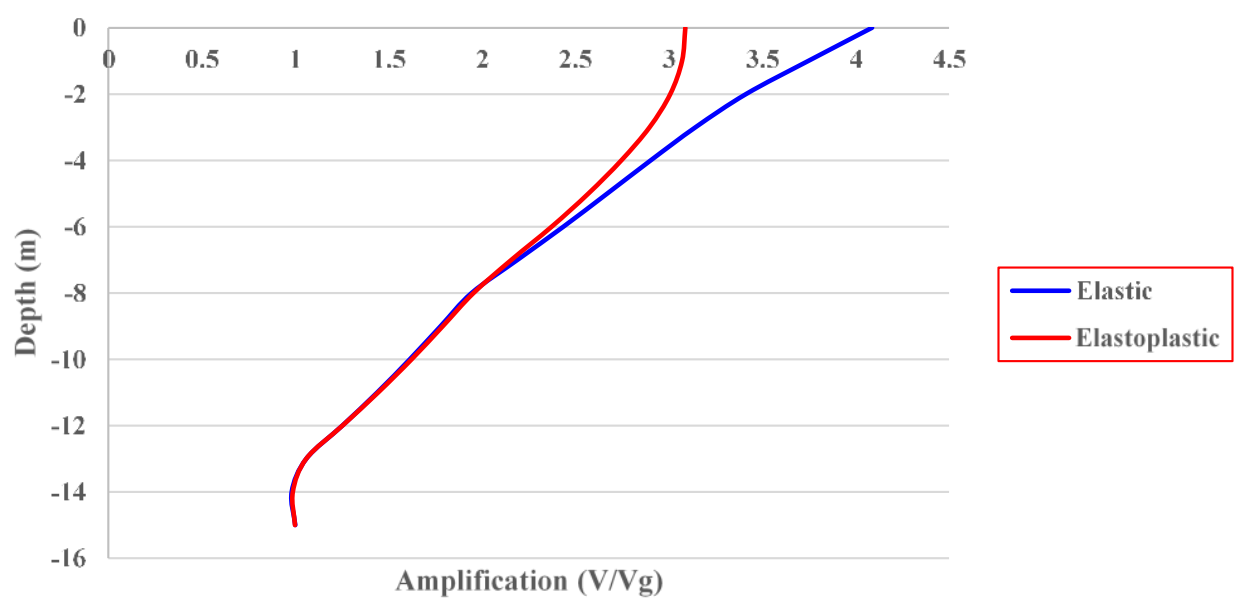

Fig. 5. Influence of soil model on response in case of MDOF building (cohesive soil, velocity amplification along y axis). 
Table 2. Displacements, velocities, at 3 considered points for elastic and elastoplastic behaviour.

\begin{tabular}{|c|c|c|c|}
\hline Soil Model & Point & Displacement (m) & Velocity (m/s) \\
\hline \multirow{3}{*}{ Elastic } & $\mathrm{A}$ & 1.187 & 8.139 \\
\cline { 2 - 4 } & $\mathrm{B}$ & 0.245 & 1.706 \\
\cline { 2 - 4 } & $\mathrm{C}$ & 0.1823 & 1.212 \\
\hline \multirow{3}{*}{ Elastoplastic } & $\mathrm{A}$ & 0.5405 & 2.357 \\
\cline { 2 - 4 } & $\mathrm{B}$ & 0.1964 & 1.253 \\
\cline { 2 - 4 } & $\mathrm{C}$ & 0.1903 & 1.192 \\
\hline
\end{tabular}

\section{Conclusion}

This paper included a numerical analysis on the effect of the soil model on the seismic response of structures braced with shear walls and on the soil-structure interaction phenomenon. The study was carried out using a full 3D global dynamic analysis in the time domain. Numerical simulations show that the soil-foundation-structure interaction depend on several parameters mainly the frequency content, the amplitude of the ground motion and the soil non linearity. The soil plasticity should be introduced in the analysis of the soil structure interaction for moderate and severe seismic motions since it leads to a significant attenuation of the seismic response of the soil beneath the foundation level and consequently to a significant reduction of the lateral amplification of the superstructure movement and the resulting internal forces.

\section{References}

1. G. Gazetas, G. Mylonakis. Seismic Soil-Structure Interaction: New Evidence and Emerging Issues. Emerging Issues Paper, Geotechnical Special Publication No. 75, vol. 3. ASCE: New York, 1998; 1119-1174.

2. G. Mylonakis, G. Gazetas. Seismic soil-structure interaction: beneficial or detrimental? Journal of Earthquake Engineering 2000; 4(3):277-301. DOI: 10.1142/S1363246900000175.

3. G. Mylonakis, S. Nikolaou, G. Gazetas. Footings under seismic loading: Analysis and design issues with emphasis on bridge foundations. Soil Dynamics and Earthquake Engineering, Volume 26, Issue 9, September 2006, 824 -853.

4. E. Kausel. Early history of soil-structure interaction. Soil Dynamics and Earthquake Engineering, Volume 30, Issue 9, September 2010, 822 - 832.

5. K. Khalil, M. Sadek, I. Shahrour. Influence of the soil-structure interaction on the fundamental period of buildings. Earthquake Engineering and Structural Dynamics, Wiley, 2007; 36:2445-2453.

6. A. Halabian, H. El Naggar. Effect of non-linear soil-structure interaction on seismic response of tall slender structures. Soil Dynamics and Earthquake Engineering, Volume 22, Issue 8, October 2002, $639-658$.

7. H. Gullu, H. Salih Jaf. Full 3D Nonlinear Time History Analysis of Dynamic SoilStructure Interaction for a Historical Masonry Arch Bridge. Environmental Earth Sciences, Volume 75, Issue 21, November 2016, 541 - 551. 
8. A. Amorosi, D. Boldini, A. Di Lernia. Dynamic Soil Structure Interaction: A Threedimensional Numerical Approach and its Application to the Lotung Case Study. Computers and Geotechnics, Volume 90, October 2017, 34 - 54.

9. M. Atik, M.M. Badawi, I. Shahrour, M. Sadek. Optimum level of shear wall curtailment in wall-frame buildings: The continuum model revisited. Journal of Structural Engineering, ASCE, Volume 140, Issue 1, January 2014.

10. M. Atik, M. SADEK, I. Shahrour. Chapter 3: Single-Run Adaptive Pushover Procedure for Shear Wall Structures, DOI: 10.4018/978-1-5225-2089-4.ch003. In book: Performance-Based Seismic Design of Concrete Structures and Infrastructures, IGI Global, Hershey PA, USA 17033. (ISSN: 2326-6139; eISSN: 2326-6155), 2017.

11. Y. Parish, M. Sadek, I. Shahrour. Numerical analysis of the seismic behaviour of earth dam. Natural Hazards and Earth System Sciences, Copernicus, 9, 451-458, 2009.

12. M. Mhanna, I. Shahrour, M. Sadek, P. Dunez. Efficiency of heavy mass technology in traffic vibration reduction: Experimental and numerical investigation. Computers and Geotechnics, Elsevier, Volume 55, January 2014, Pages 141-149. 